\title{
Natural and synthetic pathogen associated molecular patterns modulate galectin expression in cow blood
} \author{
and Mulumebet Worku \\ ${ }^{1}$ Department of Agriculture- Animal Science, University of Arkansas at Pine Bluff, AR 71601, USA \\ ${ }^{2}$ Department of Animal Sciences, North Carolina A\&T State University, Greensboro, NC 27411, USA \\ ${ }^{3}$ Department of Biology, North Carolina A\&T State University, Greensboro, NC 27411, USA \\ ${ }^{4}$ Functional and Chemical Genomics, Oklahoma Medical Research Foundation, OK 73104, USA
}

Emmanuel Kwaku Asiamah ${ }^{1 *}$, Kingsley Ekwemalor ${ }^{2}$, Sarah Adjei-Fremah ${ }^{3}$, Bertha Osei $^{4}$, Robert Newman $^{3}$

\section{Abstract}

Pathogen-associated Molecular Patterns (PAMPs) are highly conserved structural motifs that are recognized by Pathogen Recognition receptors (PRRs) to initiate immune responses. Infection by these pathogens and the immune response to PAMPS such as lipopolysaccharide (LPS), Peptidoglycan (PGN), bacterial oligodeoxynucleotides [CpG oligodeoxynucleotides 2006 (CpG ODN2006) and CpG oligodeoxynucleotides 2216 (CpG ODN2216)], and viral RNA Polyinosinic-Polycytidylic Acid (Poly I:C), are associated with infectious and metabolic diseases in animals impacting health and production. It is established that PAMPs mediate the production of cytokines by binding to PRRs such as Toll-like receptors (TLR) on immune cells. Galectins (Gal) are carbohydrate-binding proteins that when expressed play essential roles in the resolution of infectious and metabolic diseases. Thus it is important to determine if the expression of galectin gene (LGALS) and Gal secretion in blood are affected by exposure to LPS and PGN, Polyl:C and bacterial CpG ODNs. LPS increased transcription of LGALS4 and 12 (2.5 and 2.02 folds respectively) and decreased secretion of Gal $4(p<0.05)$. PGN increased transcription of LGALS-1, $-2,-3,-4,-7$, and $-12(3.0,2.3,2.0,4.1,3.3$, and 2.4 folds respectively) and secretion of Gal-8 and Gal$9(p<0.05)$. Poly I:C tended to increase the transcription of LGALS1, LGALS4, and LGALS8 $(1.78,1.88$, and 1.73 folds respectively). Secretion of Gal-1, $-3,-8$ and nine were significantly increased in treated samples compared to control $(p<$ 0.05). CpG ODN2006 did not cause any significant fold changes in LGALS transcription (FC $<2$ ) but increased secretion of Gal-1, and-3 $(p<0.05)$ in plasma compared to control. Gal-4 was however reduced in plasma $(p<0.05)$. CpG ODN2216 increased transcription of LGALS1 and LGALS3 (3.8 and 1.6 folds respectively), but reduced LGALS2, LGALS4, LGALS7, and LGALS12 (-1.9, $-2.0,-2.0$ and; -2.7 folds respectively). Secretion of Gal-2 and -3 in plasma was increased compared to control $(p<0.05)$. Gal-4 secretion was reduced in plasma $(p<0.05)$. The results demonstrate that PAMPs differentially modulate galectin transcription and translation of galectins in cow blood.

Keywords: PAMPs, Galectins, Cow, Disease

Received: Jan 23, 2019 Revised: Aug 1,2019 Accepted: Sept 5,2019

"Corresponding author: Emmanuel Kwaku Asiamah, Department of Agriculture- Animal Science, University of Arkansas at Pine Bluff, AR 71601, USA.

Tel: +1-870-575-8981, E-mail: asiamahe@uapb.edu

This is an Open Access article distributed under the terms of the Creative Commons Attribution Non-Commercial License (http://creativecommons.org/licenses/by$\mathrm{nc} / 4.0 /$ ) which permits unrestricted non-commercial use, distribution, and reproduction in any medium, provided the original work is properly cited.

Copyright (C) 2019 Korean Society of Animal Science and Technology. 


\section{Background}

Cows are infected by numerous pathogens that affect their productivity and health.These pathogens include bacteria, protozoa, and viruses. Diseases caused by pathogens affect the profitability of rearing animals [1,2]. Pathogen-associated Molecular Patterns (PAMPs) are recognized by pathogen recognition receptors (PRRs) on host cells to trigger immune responses [3]. Lipopolysaccharide (LPS), peptidoglycan (PGN), double-stranded viral RNA (Poly $\mathrm{I}: \mathrm{C})$ and bacterial oligonucleotides ( $\mathrm{CpG} \mathrm{ODNs}$ ) are associated with infectious and metabolic diseases in the cow [2,4-6]. PAMPs mediate the production of cytokines by primarily binding to PRRs, such as TLRs on immune cells to activate several signaling pathways [7-9]. There are 10 TLRs identified in cows that recognize PAMPs [10]. Previous studies have reported that the increase of LPS in the digestive tract of the cow phenomenon called subacute ruminal acidosis, and its translocation into the bloodstream, results in immune responses which if not controlled, causes serious health consequences [11]. Proper recognition and elimination is essential to animal health and production [12]. Aside from TLRs, other receptors and co-receptors play significant roles in recognition and pathogen elimination.

Numerous studies have shown that Gal, a family of proteins defined by their affinity for $\beta$-galactosides, participate in the regulation of both innate and adaptive immunity [13-15].

Some galectins have been studied to bind microorganism-specific glycans, or host-like glycans on microorganisms to initiate immune responses [16]. Galectin mediated immune response could either lead to clearance of microorganism or favor establishment of the pathogens. Galectins (Gal) act as PRRs that orchestrate immune responses according to the level of pathogenicity of the invading microorganisms [17]. Some members of the galectin family are also known alarmins for sepsis, a condition caused by an overwhelming immune response to microbial infection [18].

The most significant advancement in animal health in the past three decades has been the paradigm shift from treatment of clinical illness to disease prevention [19]. Overuse of antibiotics in animal production has raised food safety and public health concerns in addition to its reduced effectiveness and resistance in animals [20]. As such, numerous studies are emerging to better understand the molecular mechanisms leading to infectious diseases to design more effective management practices to reduce cow health disorders $[7,8]$. An increased understanding of the genetics underlying the immune response mechanism of cows during infections may offer opportunities for alternative control strategies.

Because galectins are involved in immune responses and the outcome of microbial infections, it was essential to evaluate whether its expression in cows is affected by pathogen-associated molec- ular patterns (PAMP) stimulation in whole blood. Understanding galectin expression in response to PAMP stimulation will aid in drug design aimed at galectins as targets. This study aimed to evaluate the effect of stimulation with known PAMPs (natural and synthetic) on galectin gene expression in cow blood.

\section{Materials and Methods}

\section{Animals}

The Institutional Animal Care and Use Committee of North Carolina A\&T State University approved all protocols for animals handling. Five multiparous Holstein Friesian periparturient cows $(\mathrm{N}=5)$ from North Carolina A\&T State Dairy farm were used. None of the animals showed any signs of disease or received medications during the 4-week period before blood sampling.

\section{Blood sampling}

Complete details of blood sampling have been reported elsewhere [21]. Briefly, Whole blood $(10 \mathrm{~mL})$ was collected aseptically from the jugular vein of the animals into vacutainer tubes containing $1 \mathrm{~mL}$ of the anti-coagulant Acid Citrate Dextrose. The tubes were gently mixed and placed on ice immediately after collection. The samples were transported to the Laboratory for Animal Genomic Diversity and Biotechnology at North Carolina A\&T State University for further analysis.

\section{Stimulation of whole blood}

One $\mathrm{mL}$ of blood from the cows was each incubated with $10 \mu \mathrm{g} /$ $\mathrm{mL}$ each of either Escherichia coli derived LPS (Sigma-Aldrich, St. Louis, MO), Staphylococcus aureus-derived PGN (Sigma-Aldrich), CpG ODN (2216) class A (Invivogen, San Diego CA ), CpG ODN (2006) class B (Invivogen) and $12.5 \mu \mathrm{g} / \mathrm{mL}$ of poly I:C (Invivogen) individually to assess the expression of LGALS. Samples treated with phosphate buffer saline (PBS) served as control. Samples were incubated at $37^{\circ} \mathrm{C}$, with $85 \%$ humidity and $5 \% \mathrm{CO}_{2}$ for 30 minutes. At the end of the incubation period, the tubes were spun down at $1,700 \times \mathrm{g}$ at $4^{\circ} \mathrm{C}$ for 10 minutes. Supernatants were collected and stored at $-80^{\circ} \mathrm{C}$ to measure secreted galectins concentration. Trizol $(1 \mathrm{~mL})$ was added to cell pellets and stored for RNA isolation $\left(\right.$ Ambion $^{\circledR}$, Thermo Fisher Scientific Inc, Waltham, $\mathrm{MA})$.

\section{Total RNA isolation and cDNA synthesis}

Total RNA was isolated using Trizol according to the manufacturer's instructions (Sigma-Aldrich St. Louis, MO). The appropriate precautions were used to avoid RNase contamination throughout the entire procedure [9]. The RNA concentration $(\mathrm{ng} / \mu \mathrm{L})$ and $\mathrm{pu}-$ rity (260/280) were assessed using a Nanodrop Spectrophotometer 
ND 1000 (Thermo Scientific Inc., Waltham, MA). Total RNA was pipetted into an RNA 6000 Nano LabChip ${ }^{\circledR}$ (Agilent Technologies, Santa Clara, CA) and RNA integrity was determined using Bioanalyzer following manufacturer's protocol (Agilent). Complimentary DNA (cDNA) synthesis was performed with $500 \mathrm{ng} / \mu \mathrm{L}$ RNA (purity 260/280 = 1.8, RIN = 7). Retroscript kits $\left(\right.$ Ambion ${ }^{\circledR}$ ) were used to synthesize cDNA for real-time Polymerase chain reaction. cDNA synthesis was performed in an MWG AG Biotech Primus 96 Plus Industrial Lab Thermal Cycler (MWG Biotech Huntsville, AL). Total RNA $(1 \mu \mathrm{g})$ was heated to $85^{\circ} \mathrm{C}$ for 3 minutes and placed on ice, centrifuged briefly, and returned to ice. The remaining RETROscript ${ }^{\circledR}$ components were added: 10X RT (PCR) buffer $(2 \mu \mathrm{L})$, dNTP mix $(4 \mu \mathrm{L})$, RNase inhibitor $(1 \mu \mathrm{L})$, and MMLV-RT $(1 \mu \mathrm{L})$, for a final volume of $20 \mu \mathrm{L}$. The components were mixed gently, centrifuged briefly and incubated at $42-44^{\circ} \mathrm{C}$ for 1 hour, followed by an incubation step at $92^{\circ} \mathrm{C}$ for 10 minutes to inactivate the Reverse Transcriptase (RT). Polymerase chain reaction was performed by assembling the following components: RT reaction buffer $(5 \mu \mathrm{L}), 10 \mathrm{X}$ PCR buffer $(5 \mu \mathrm{L})$, dNTP $(2.5 \mu \mathrm{L})$, Nuclease-free water $(37.5 \mu \mathrm{L})$, PCR primers (provided in kit) $(2.5 \mu \mathrm{L})$, and thermostable DNA Polymerase (1-2 units (U)). The PCR cycle was: Step 1) Initial denaturation, $94^{\circ} \mathrm{C}$ for 2 minutes; Step 2) Amplification, $94^{\circ} \mathrm{C}$ for 30 seconds (denaturation), $60^{\circ} \mathrm{C}$ (annealing) for 30 seconds, $72^{\circ} \mathrm{C}$ (extension) for 1 minute; Step 3) to Step 2 for 30 cycles; and Step 4) Final Extension, $72^{\circ} \mathrm{C}$ for 5 minutes.

\section{Gene expression profiling}

With the use of Primer-3 online tool (http://bioinfo.ut.ee/primer3-0.4.0/), Forward and reverse primers for cow galectin genes LGALS1, 2, 3, 4, 7, 8, 9, 12, and 15 were designed commercially. Based on published sequences, cow specific Glyceraldehyde 3-phosphate dehydrogenase (GAPDH) and $\beta$ actin were purchased from MWG, Biotech Huntsville AL. $\beta$-actin and GAP$\mathrm{DH}$ were used as internal controls and for normalization.

\section{Real-time qPCR}

Real-time qPCR was performed in the CFX Connect real-time system (Bio-rad Laboratories, Hercules, CA). The qPCR reaction mixture consisted of template, primer $(\mu \mathrm{L})$, intercalating dye SYBR Green, $\mathrm{DH}_{2} \mathrm{O}, 200 \mathrm{ng}$ of cDNA, $1 \mu \mathrm{L}(100 \mu \mathrm{M})$ of forward primer, $1 \mu \mathrm{L}(100 \mu \mathrm{M})$ of reverse primer, $10 \mu \mathrm{L}$ of SYBR Green and $\mathrm{DH}_{2} \mathrm{O}$ to the volume of $20 \mu \mathrm{L}$.

All samples were carried out in triplicate $20-\mu \mathrm{L}$ reactions in $96-$ well plates, and a negative control with no cDNA template were included in every run. The run program used were: Step 1) $95^{\circ} \mathrm{C}$ for 15 seconds for denaturing, Step 2) $60^{\circ} \mathrm{C}$ for 30 seconds for primer annealing, and $72{ }^{\circ} \mathrm{C}$ for elongation. Step 3) to Step 2 for
30 cycles; and Step 4) Final Extension, $72{ }^{\circ} \mathrm{C}$ for 5 minutes. Specificity of the amplicon products was confirmed by visual inspection of melting curves. Real-time PCR data was analyzed using the Livak's method [22]. The housekeeping genes (GAPDH and $\beta$ actin) and samples from far-off/PBS treated cows were used to determine the $\Delta \Delta \mathrm{Ct}$ [22]. Fold change in transcript abundance was calculated using the Livak method. Where

$$
\begin{aligned}
\Delta \mathrm{Ct} & =(\text { Target genes treat }-\mathrm{GAPDH} / \beta \text { actin treat }) \\
& -\Delta \mathrm{Ct} \text { (Target genes PBS }-\mathrm{GAPDH} / \beta \text { actin PBS }) .
\end{aligned}
$$

Fold change $=2(-\Delta \Delta \mathrm{Ct})$.

\section{Evaluation of galectin secretion}

Commercial bovine specific galectin ELISA kits were purchased and used to determine the concentrations of secreted Gal-1 (catalog no. MBS2882620, detection range; $0.31 \mathrm{ng} / \mathrm{mL} \& 20.0 \mathrm{ng} / \mathrm{mL}$ ), Gal-2 (catalog no. MBS033680 detection range; $0.625 \mathrm{ng} / \mathrm{mL} \&$ 20 ng/mL), Gal-3 (catalog no. MBS017323 detection range; 0.156 $\mathrm{ng} / \mathrm{mL} \& 10 \mathrm{ng} / \mathrm{mL}$ ), Gal-4 (catalog no. MBS028694, detection range; $0.25 \mathrm{ng} / \mathrm{mL} \& 8 \mathrm{ng} / \mathrm{mL}$ ), Gal-8 (catalog no. MBS041856 detection range; $0.5 \mathrm{ng} / \mathrm{mL} \& 16 \mathrm{ng} / \mathrm{mL}$ ), Gal-9 (catalog no. MBS033074 detection range; $0.625 \mathrm{ng} / \mathrm{mL} \& 20 \mathrm{ng} / \mathrm{mL}$ ), Gal12 (catalog no. MBS032400, detection range; $31.2 \mathrm{pg} / \mathrm{mL} \& 1,000$ $\mathrm{pg} / \mathrm{mL}$ ) in plasma according to the manufacturer's instructions (My BioSource $\left.^{\circledR}\right)$ ) [23]. A microplate reader was used to measure the absorbance at $450 \mathrm{~nm}$ (BioTek Instruments, Inc., Winooski, VT). Galectin concentration was then determined using a standard curve. The sensitivity was $0.1 \mathrm{ng} / \mathrm{mL}$ for all assays. Both intraassay CV (\%) and inter-assay CV (\%) for all assays was less than $15 \%$. $[\mathrm{CV}(\%)=\mathrm{SD} /$ mean $\times 100]$.

\section{Statistical analysis}

Real-time PCR data were analyzed using Livak's method [22]. Housekeeping genes (GAPDH and $\beta$ actin) and samples from PBS treated samples were used to determine the $\Delta \Delta \mathrm{Ct}$, as described above. The Proc GLM procedure in SAS 9.4 (SAS Institute Inc, Cary NC) was used to analyze data obtained for total galectins concentrations. Each sample was assayed in triplicates. The PDIFF statement in SAS (SAS Institute Inc. Cary, NC) was used to compare all least square means. Significant differences were declared at $p<0.05$. PROC corr was used to do a correlation analysis between $L G A L S$ and $\mathrm{Gal}$ concentrations in plasma.

\section{Results}

\section{Effect of PAMPs on LGALS transcription}

LPS increased transcription of LGALS4 and LGALS12 (2.5 and 2.02 folds respectively) (Fig. 1A). PGN increased transcription of $L G A L S-1,-2,-3,-4,-7$, and -12 (3.0, 2.3, 2.0, 4.1, 3.3, 2.4 


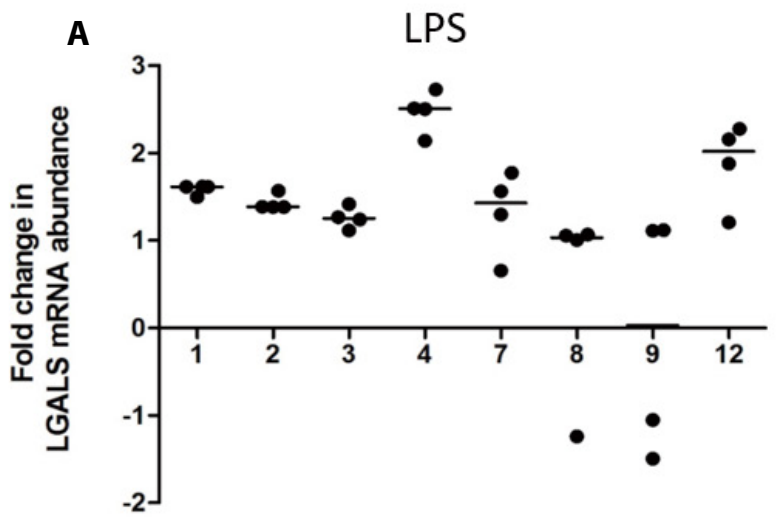

LGALS

C

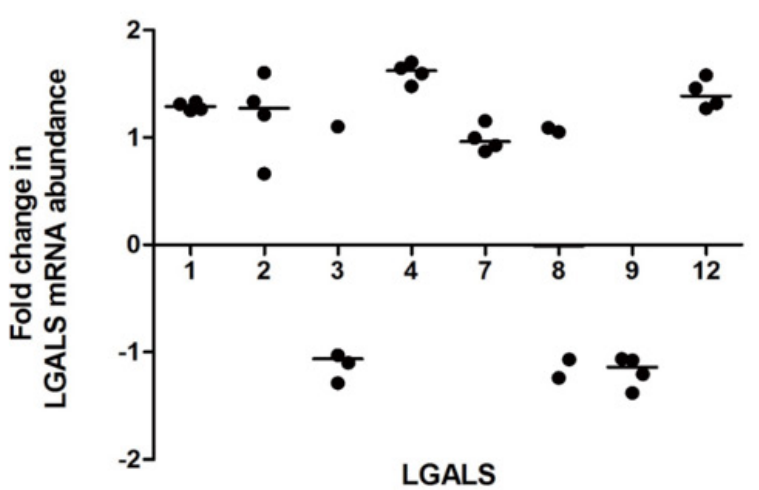

B

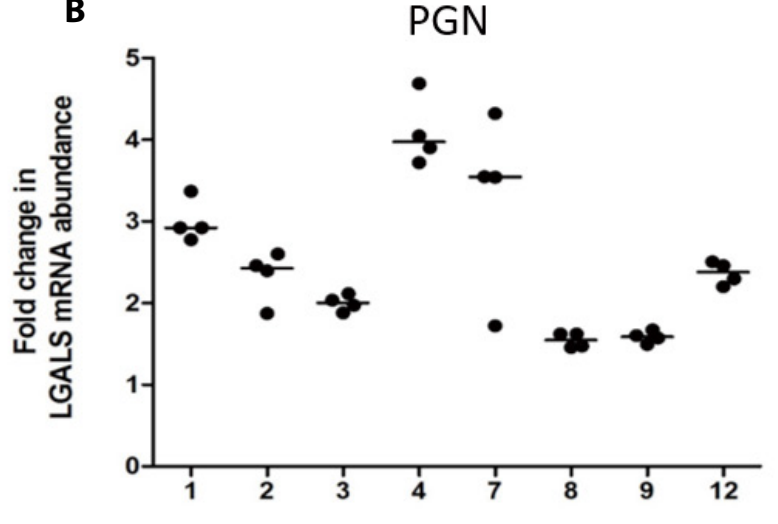

LGALS

D

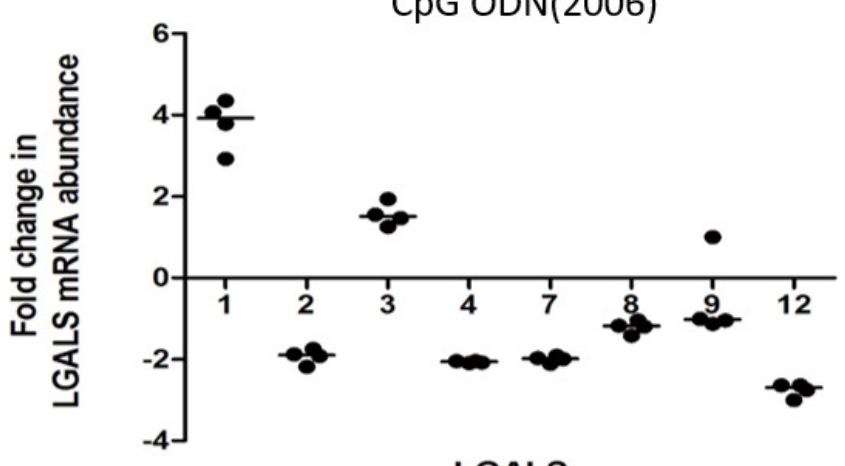

LGALS

Fig. 1. Fold changes in mRNA expression of LGALS-1, -2, -3-,4, -7, -8, -9, and -12 after stimulation of whole blood with LPS (A), PGN (B), POLY I: $C$ (C), CpG ODN 2006 (D). Error lines represent the \pm standard deviation of the mean.

folds respectively) (Fig. 1b). Poly I:C increased the transcription of LGALS1, LGALS4, and LGALS8 (1.78, 1.88, and 1.73 folds respectively) (Fig. 1c). CpG oligodeoxynucleotides 2006 (CpG ODN2006) did not cause any significant fold changes in LGALS transcription $(\mathrm{FC}<2)$ (Fig. 1d). $\mathrm{CpG}$ oligodeoxynucleotides 2216 (CpG ODN2216) increased transcription of LGALS1 and $L G A L S 3$ (3.8 and 1.6 respectively), but reduced $L G A L S 2$, LGALS4, LGALS 7, and LGALS12 (-1.9,-2.0,-2.0 and -2.7) (Fig. 2).

\section{Effects of PAMPs on galectin secretion}

Poly I:C and CpG ODN2006 increased plasma secretion of Gal1 compared to control (PBS) ( $p=0.10$ and $p=0.0125$ respectively) (Fig. 3a). CpG ODN 2216 increased Gal-2 concentration in plasma compared to control (PBS) $(p=0.0459)$ (Fig. 3b). CpG ODN 2216 and $\mathrm{CpG}$ ODN 2006 increased Gal-3 compared to control (PBS) ( $p=0.013$ and $p=0.0195$ respectively) (Fig. 3c). LPS, CpG ODN2216, and CpG ODN2006 reduced Gal-4 concentrations in plasma compared to control (PBS) $(p=0.04, p=0.0005$ and $p$
$=0.0273$ respectively (Fig. 4a). PGN and Poly I:C increased Gal-

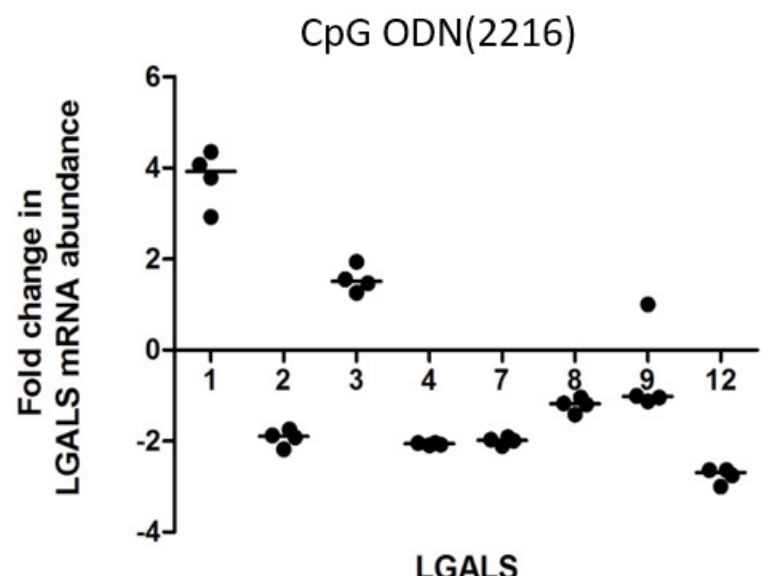

Fig. 2. Fold changes in mRNA expression of LGALS-1, -2, -3-,4, -7, $-8,-9$, and -12 after stimulation of whole blood with CpG ODN (2216) class $\mathbf{A}(\mathbf{N}=5)$. Error lines represent the \pm standard deviation of the mean. 

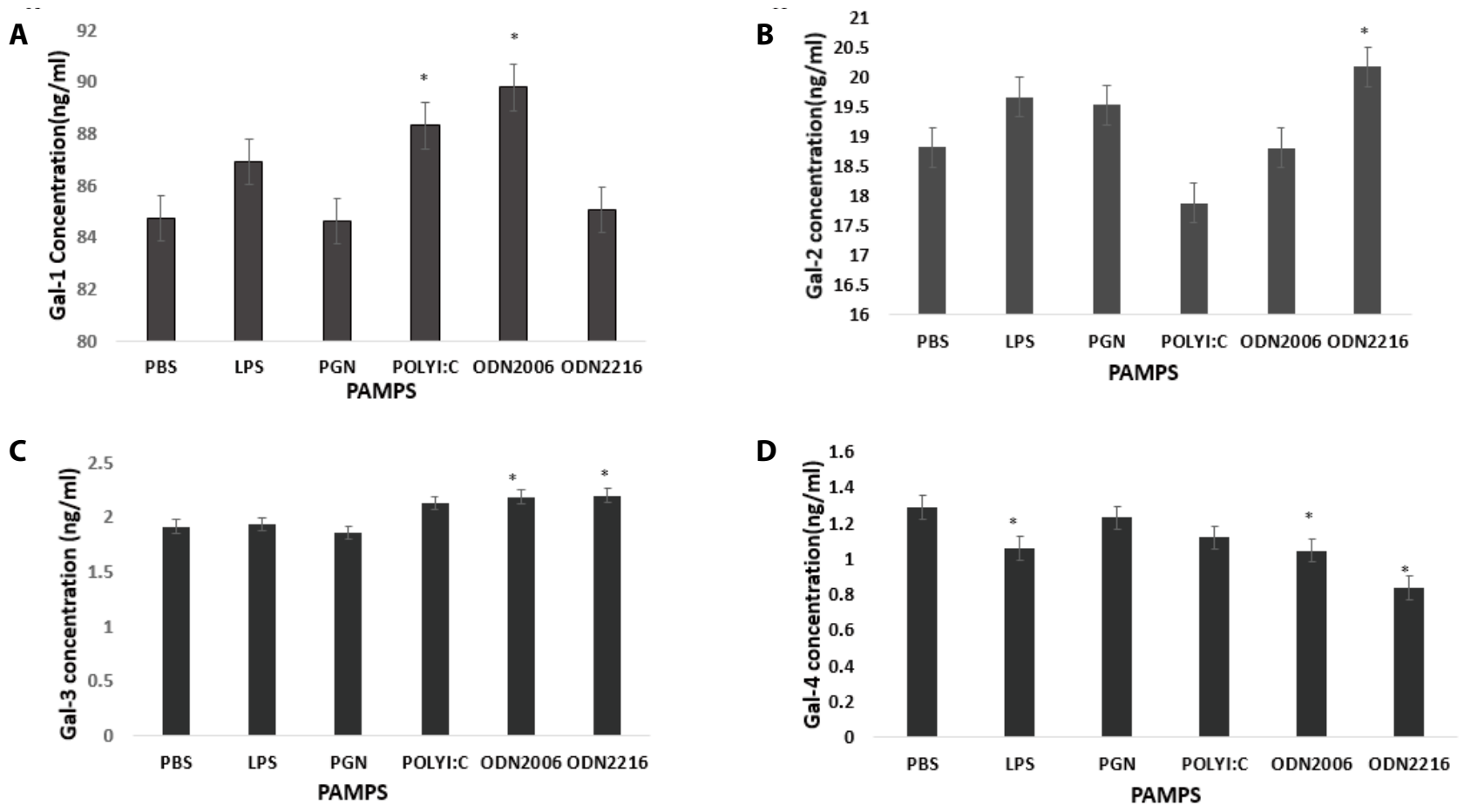

Fig. 3. Effects of stimulating cow blood from multiparous Holstein with Lipopolysaccharide (LPS), Peptidoglycan (PGN), PolyinosinicPolycytidylic Acid (Poly I:C), CpG ODN (2216) class A, CpG ODN (2006) class B on plasma Gal-1 (A), Gal-2 (B), Gal-3 (C), and Gal-4 (D) (N = 5). Error lines represent the \pm standard deviation of the mean. *significantly different from the control (PBS) at $p<0.05$.

A

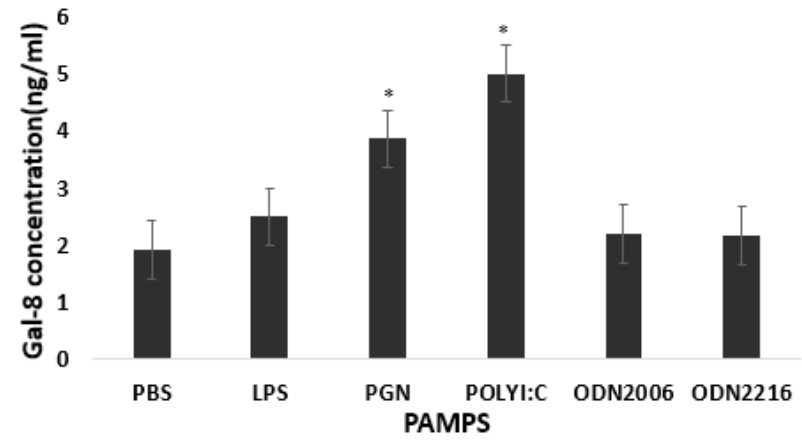

C

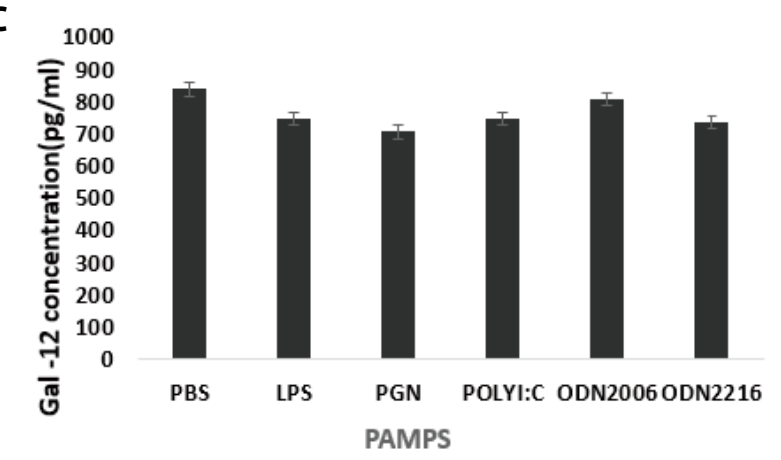

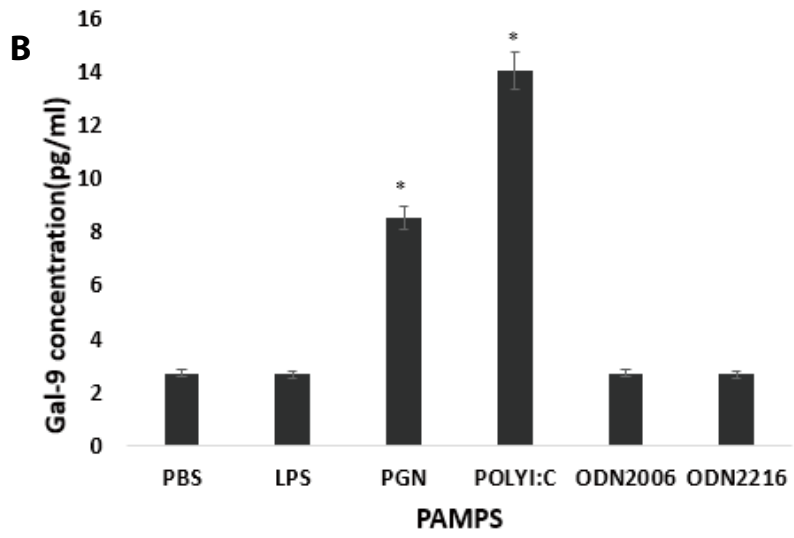

Fig. 4. Effects of stimulating cow blood from multiparous Holstein with Lipopolysaccharide (LPS), Peptidoglycan (PGN), Polyinosinic-Polycytidylic Acid (Poly I:C), CpG ODN (2216) class A, CpG ODN (2006) class B on plasma Gal-8 (A), Gal-9 (B) and Gal-12 (C) (N = 5). Error lines represent the \pm standard deviation of the mean. *significantly different from the control (PBS) at $p<0.05$. 
8 secretion compared to control (PBS) $(p=0.001$ and $p<.0001$ respectively (Fig. 4a). PGN and Poly I:C increased Gal-9 secretion compared to control (PBS) $(p=0.001$ and $p<.0001$ respectively) (Fig. 4b). PAMPs did not affect plasma concentration of Gal-12 ( $p$ $>0.05$ ) (Fig. 4c).

\section{Analysis of correlation between galectin transcription and secretion}

LGALS1 correlated negatively with Gal-1 $(p=0.02)$ and correlated positively with Gal-2 $(p=0.03)$. LGALS2 correlated positively with Gal-4 $(p=<0.0001)$ and Gal-3 $(p=0.0009)$. LGALS3 correlated negatively with Gal-1 $(p=0.006)$ and Gal-3 $(p=0.05)$. LGALS4 correlated positively with Gal-4 $(p=<0.0001)$ and negatively with Gal-3. LGALS8 correlated positively with Gal-8 $(p=<0.0001)$, Gal-9 $(p=<0.0001)$ and Gal-4 $(p=0.0002)$, and negatively with Gal-2 $(p=<0.0002) . L G A L S 9$ correlated positively with Gal-9 ( $p$ $=0.007), \mathrm{Gal}-8(p=0.0006)$ and Gal-4 $(p=0.002)$, and negatively with Gal-3.

LGALS12 correlated positively with Gal-4 $(p=<0.0001)$ and negatively with $\mathrm{Gal} 3$ ( $p=0.0073)$.

\section{Discussion}

In the past few years, galectins have been shown to participate in the regulation of both innate and adaptive immunity [13,24]. Furthermore, there is research that supports the ability of Gals to recognize microbial pathogens like viruses, bacteria and protozoan parasites [15] directly. The ability of Gals to function as PRRs in the immune defense against invading microbes makes them indispensable components in the innate immune response [16]. To test whether microbial infection affects galectin expression in cow blood, we treated blood with natural bacteria cell wall components (LPS and PGN), synthetic bacterial DNA adjuvants (CpGODN2006 and CpGODN2216) and viral RNA (Poly I:C). Treatment of cells with PAMPs mimic microbial infection and regulates expression of various genes [25]. The current study showed that PAMP modulates LGALS gene transcription as well as Gal secretion differentially in cow blood. Both transcription and secretion depended on the type of stimulant used.

Bacterial LPS and PGN designated PAMPs, are recognized by TLR-4 and TLR-2 respectively [26]. The binding of these PAMPs to their receptors is characterized by transcription of genes involved in immune responses and secretion of cytokines $[8,9,27]$. In the present study, LPS stimulation increased the transcription of LGALS4 and LGALS12 in cow blood (Fig. 1a). Gal-4 has been studied to be only expressed in inflamed cells and therefore has a more restricted distribution in normal cells [28]. Gal-4 also promotes resolution of inflammatory diseases, therefore, making it an important player in immune responses [29]. Gal-12, on the other hand, is preferentially expressed in adipose tissues and has also been studied to be associated with impaired metabolic conditions [30]. Both Gal-4 and Gal-12 exert regulatory functions in immune cells and have strong potential as biomarkers. This data suggests a possible role of Gal-4 and - 12 in the recognition and resolution of gram-negative bacteria in cows. The relationship between LPS and the transcription of these galectins need to be explored.

The gram-positive bacterial cell wall, PGN also increased transcription of LGALS4 and LGALS12 as well as all galectins tested. The differential $L G A L S$ transcription and secretion in response to LPS and PGN observed in the study suggest distinct immunological activities in response to these PAMPs. This also accentuates the fact that both gram-positive and gram-negative are recognized by different receptors to elicit different immunological responses. Thus, either LPS or PGN can be used as adjuvants to induce the production of different galectins.

Recently, galectins have been observed to interact directly with the $\beta$-galactosides on the surface of viruses thereby participating in antiviral defense, via the activation of the innate and adaptive immune responses [31,32]. Previous research has shown that viral infection has modulatory effects on galectin expression and function [33]. In this study, galectin expression in blood in response to viral challenge assessed by a PolyI:C challenge. Poly I:C is a viral PAMP that promotes cellular recognition of RNA viruses by binding to TLR3 to induce proinflammatory, as well as regulatory and cytokine responses [34]. In this study, Poly I:C increased the transcription of LGALS1, LGALS4, and LGALS8 with a subsequent secretion of Gal-1, -3, -8 and 9 in plasma. In a previous study, secretion of several galectins, including Gal-1 and -3 were increased in virus-infected macrophages [35]. Gonzalez et al. (2005) has also postulated that induced Gal-1 secretion after a viral infection is beneficial for the virus due to its anti-inflammatory functions [31]. On the contrary, Gal-3 has opposing functions since it recruits inflammatory cells to the site of infection. It is possible that the balance between the secreted extracellular Gal-1 and -3 in the current may regulate the direction of the inflammatory response in cows. It is also noteworthy that Gal-8, which has been known to be involved in phagocytosis [36] is transcribed and secreted upon viral PAMP stimulation. The current study suggests that these galectins may also be involved in recognition of viral PAMPs and promote the removal of these viral pathogens through phagocytosis, or prevent viruses from entering the host cell.

Studies have indicated that oligodeoxynucleotides $(\mathrm{CpG}$ ODNs) containing unmethylated $\mathrm{CpG}$ dinucleotides are potent activators of both innate and adaptive immunity [37]. CpG ODNs are recognized by the Toll-like receptor 9 (TLR9) [38]. The TLR9 signaling pathway involves mitogen-activated protein kinases, and 
NF-kB-inducing kinase-IKK- Inhibitor of KappaB Kinase (IkB) pathways [39]. Both CpG ODN 2216 and CpG ODN 2006 have been studied to show distinct functional profiles depending on the type of $\mathrm{CD} 8^{+}$cells they are exposed to. CpG ODN 2216 induces high amounts of interferon alpha in plasmacytoid dendritic cells whereas CpG ODN2006 only induces small amounts of IFN alpha [40]. Furthermore, CpG ODN2006 has also been studied to be a weak activator of natural killer cells compared to $\mathrm{CpG}$ ODN2216 [41]. This proves that both CpG ODN motifs show distinct immunologic activities. In the present study, the 2 types of CpG ODN adjuvants also affected $L G A L S$ transcription and secretion distinctively in cow blood. Although no fold changes were observed in LGALS transcription ( $\mathrm{FC}<2$ ), CpG ODN2006 treatment increased secretion of Gal-1 and Gal3 in plasma (Fig. 1d). This increase supports the proinflammatory roles of $\mathrm{CpG}$ ODNs since Gal-1 and Gal-3 are proinflammatory in pathogenic conditions. CpG ODN2216, however, increased Gal-2, a pro-apoptotic galectin and $\mathrm{Gal}-3$, a proinflammatory galectin. This also points to a balance in immune response upon PAMP recognition. Improper orchestration of the immune response to microbial infections may lead to sepsis, a condition caused by an overwhelming immune responses [7].

It was also important to note from this study that although LPS and the CpG ODNs motifs are both of bacteria origin, LPS did not affect galectin secretion in plasma. This could mean that $\mathrm{Gal}$ secretion in cow blood is increased in response to bacteria DNA compared to its cell wall components. The concentration of LPS (10 $\mu \mathrm{g})$ used as well as the length of exposure could also cause variation in transcription and translation in blood [42]. Also, the fact that transcription of LGALS4 was reduced in blood treated the $\mathrm{CpG}$ ODN motifs is noteworthy since both PAMPs are synthetic adjuvants. This points to a negative regulatory effect of these PAMPs on LGALS4. The results of this study have implications for vaccination and use of synthetic PAMPs in cows and immunomodulation.

\section{Conclusion}

The results demonstrate that PAMPs differentially modulate transcription of mRNA and secretion of Gal in cow blood. Elucidation of the relationship between PAMPS and galectin expression may help to define their roles in infectious diseases as well as aid in drug design for the dairy industry.

\section{Competing interests}

No potential conflict of interest relevant to this article was reported.

\section{Funding sources}

National Institute of Food and Agriculture Evans Allen funds:
Project Improving Resistance and Resilience: The Role of Galectins in Periparturient Ruminants. No. NC.X-300-5-16-120-1.

\section{Acknowledgements}

The authors are grateful to the National Institute of Food and Agriculture Evans Allen funds: Project Improving Resistance and Resilience: The Role of Galectins in Periparturient Ruminants. No. NC.X-300-5-16-120-1 for funding the research. Special thanks also go to the North Carolina Agricultural and Technical State University Dairy Unit especially, Mr. Corey Burgess for assisting with blood sampling. We would also like to thank Dr. Hamid Ismail for making sure all supplies were available to make this research possible.

\section{Availability of data and material}

Upon reasonable request, the datasets of this study can be available from the corresponding author.

\section{Authors' contributions}

Conceptualization: Worku M.

Data curation: Worku M, Asiamah EK.

Formal analysis: Worku M, Asiamah EK, Adjei-Fremah S, Ekwemalor K, Osei B.

Methodology: Worku M, Asiamah EK, Adjei-Fremah S, Ekwemalor K, Osei B.

Software: Asiamah EK, Adjei-Fremah S.

Validation: Newman R.

Investigation: Asiamah Ek, Worku M.

Writing - original draft: Worku M, Asiamah EK.

Writing - review \& editing: Worku M, Asiamah EK, Adjei-Fremah S, Ekwemalor K, Osei B, Newman R.

\section{Ethics approval and consent to participate}

All protocols for handling of animals was approved by the Institutional Animal Care and Use Committee (IACUC) of North Carolina A\&T State University.

\section{ORCID}

Emmanuel K Asiamah https://orcid.org/0000-0001-8142-6211 Kingsley Ekwemalor https://orcid.org/0000-0003-2073-2623 Sarah Adjei-Fremah https://orcid.org/0000-0001-6198-7097 Bertha Osei https://orcid.org/0000-0001-5162-3388 Robert Newman https://orcid.org/0000-0002-3865-0266 Mulumebet Worku https://orcid.org/0000-0003-3663-4745

\section{References}

1. LeBlanc SJ, Lissemore KD, Kelton DF, Duffield TF, Leslie 
KE. Major advances in disease prevention in dairy cattle. J Dairy Sci. 2006;89:1267-79.

2. Bannerman DD. Pathogen-dependent induction of cytokines and other soluble inflammatory mediators during intramammary infection of dairy cows. J Anim Sci. 2009;87 Suppl 13:10-25.

3. Sarukhan A, Martinez-Florensa M, Escoda-Ferran C, Carrasco E, Carreras E, Lozano F. Pattern recognition by CD6: a scavenger-like lymphocyte receptor. Curr Drug Targets 2016;17:640-50.

4. Schaefer TM, Fahey JV, Wright JA, Wira CR. Innate immunity in the human female reproductive tract: antiviral response of uterine epithelial cells to the TLR3 agonist poly (I:C). J Immunol. 2005;174:992-1002.

5. Nichani AK, Mena A, Popowych Y, Dent D, Townsend HG, Mutwiri GK, et al. In vivo immunostimulatory effects of $\mathrm{CpG}$ oligodeoxynucleotide in cattle and sheep. Vet Immunol Immunopathol. 2004;98:17-29.

6. Griebel PJ, Brownlie R, Manuja A, Nichani A, Mookherjee N, Popowych Y, et al. Bovine toll-like receptor 9: a comparative analysis of molecular structure, function and expression. Vet Immunol Immunopathol. 2005;108:11-6.

7. Asiamah EK, Adjei-Fremah S, Osei B, Ekwemalor K, Worku M. An extract of Sericea Lespedeza modulates production of inflammatory markers in pathogen associated molecular pattern (PAMP) activated ruminant blood.J Agr Sci. 2016;8:1.

8. Asiamah EK, Adjei-Fremah S, Ekwemalor K, Worku M. Nystatin modulates genes in immunity and wingless signaling pathways in cow blood. J Mol Biol Res. 2017;7:1.

9. Adjei-Fremah S, Ekwemalor K, Asiamah E, Ismail H, Worku M. Transcriptional profiling of the effect of lipopolysaccharide (LPS) pretreatment in blood from probiotics-treated dairy cows. Genom Data 2016;10:15-8.

10. Werling D, Jungi TW. TOLL-like receptors linking innate and adaptive immune response. Vet Immunol Immunopathol. 2003;91:1-12.

11. Plaizier JC, Krause DO, Gozho GN, McBride BW. Subacute ruminal acidosis in dairy cows: the physiological causes, incidence and consequences. Vet J. 2008;176:21-31.

12. Tilman D, Cassman KG, Matson PA, Naylor R, Polasky S. Agricultural sustainability and intensive production practices. Nature 2002;418:671-7.

13. Rabinovich GA, Baum LG, Tinari N, Paganelli R, Natoli C, Liu FT, et al. Galectins and their ligands: amplifiers, silencers or tuners of the inflammatory response? Trends Immunol. 2002;23:313-20.

14. van Kooyk Y, Rabinovich GA. Protein-glycan interactions in the control of innate and adaptive immune responses. Nat Im- munol. 2008;9:593-601.

15. Vasta GR. Galectins as pattern recognition receptors: structure, function, and evolution. Adv Exp Med Biol. 2012;946:21-36.

16. Sato S, St-Pierre C, Bhaumik P, Nieminen J. Galectins in innate immunity: dual functions of host soluble $\beta$-galactoside-binding lectins as damage-associated molecular patterns (DAMPs) and as receptors for pathogen-associated molecular patterns (PAMPs). Immunol Rev. 2009;230:172-187.

17. Wang M, Wang L, Huang M, Yi Q, Guo Y, Gai Y, et al. A galectin from Eriocheir sinensis functions as pattern recognition receptor enhancing microbe agglutination and haemocytes encapsulation. Fish Shellfish Immunol. 2016;55:10-20.

18. Mishra BB, Li Q, Steichen AL, Binstock BJ, Metzger DW, Teale JM, et al. Galectin-3 functions as an alarmin: pathogenic role for sepsis development in murine respiratory tularemia. PloS one 2013;8:e59616.

19. LeBlanc SJ, Duffield TF, Leslie KE, Bateman KG, Keefe GP, Walton JS, et al. Defining and diagnosing postpartum clinical endometritis and its impact on reproductive performance in dairy cows.J Dairy Sci. 2002;85:2223-6.

20. Oliver SP, Murinda SE, Jayarao BM. Impact of antibiotic use in adult dairy cows on antimicrobial resistance of veterinary and human pathogens: a comprehensive review. Foodborne pathog Dis. 2011;8:337-55.

21. Asiamah EK. Ex vivo effects of water extracts of sericea lespedeza on cow, sheep and goat blood [Ph.D. dissertation]. Greensboro, NC: North Carolina Agricultural and Technical State University; 2015.

22. Livak KJ, Schmittgen TD. Analysis of relative gene expression data using real-time quantitative PCR and the $2-\Delta \Delta C T$ method. methods 2001;25:402-8.

23. Asiamah EK, Adjei-Fremah S, Ekwemalor K, Sordillo L, Worku M. Parity and periparturient period affects galectin gene expression in Holstein cow blood. J Appl Biotechn. 2018;6:20.

24. Vasta GR. Roles of galectins in infection. Nat Rev Microbiol. 2009;7:424-38.

25. Kawai T, Akira S. The role of pattern-recognition receptors in innate immunity: update on toll-like receptors. Nat Immunol. 2010;11:373-84.

26. Adib-Conquy M, Cavaillon JM. Stress molecules in sepsis and systemic inflammatory response syndrome. FEBS Lett. 2007;581:3723-33.

27. Ekwemalor K, Asiamah E, Osei B, Ismail H, Worku M. Evaluation of the effect of probiotic administration on gene expression in goat blood.J Mol Biol Res. 2017;7:88.

28. Huflejt ME, Leffler H. Galectin-4 in normal tissues and cancer. Glycoconjugate J. 2003;20:247-55. 
29. Paclik D, Danese S, Berndt U, Wiedenmann B, Dignass A, Sturm A. Galectin- 4 controls intestinal inflammation by selective regulation of peripheral and mucosal $\mathrm{T}$ cell apoptosis and cell cycle. PLoS One 2008;3:e2629.

30. Yang RY, Havel PJ, Liu FT. Galectin-12: a protein associated with lipid droplets that regulates lipid metabolism and energy balance. Adipocyte 2012;1:96-100.

31. Gonzalez MI, Rubinstein N, Ilarregui JM, Toscano MA, Sanjuan NA, Rabinovich GA. Regulated expression of galectin-1 after in vitro productive infection with herpes simplex virus type I: implications for T cell apoptosis. Int J Immunopathol Pharmacol. 2005;18:615-23.

32. Rabinovich GA, Toscano MA, Jackson SS, Vasta GR. Functions of cell surface galectin-glycoprotein lattices. Curr Opin Struct Biol. 2007;17:513-20.

33. Garner OB, Aguilar HC, Fulcher JA, Levroney EL, Harrison $\mathrm{R}$, Wright $\mathrm{L}$, et al. Endothelial galectin-1 binds to specific glycans on nipah virus fusion protein and inhibits maturation, mobility, and function to block syncytia formation. PLoS pathog. 2010;6:e1000993.

34. Zhou Y, Guo M, Wang X, Li J, Wang Y, Ye L, et al. TLR3 activation efficiency by high or low molecular mass poly I: C. Innate Immun. 2013;19:184-92.

35. Miettinen J. Activation of innate immune response in human macrophages by Herpes simplex virus- 1 and crystallized monosodium urate [Ph.D. dissertation]. Helsinki, Finland: University of Helsinki; 2014.

36. Thurston TL, Wandel MP, von Muhlinen N, Foeglein A, Randow F. Galectin-8 targets damaged vesicles for autophagy to defend cells against bacterial invasion. Nature 2012;482:414-8.

37. $\mathrm{Wu}$ J, Chen ZJ. Innate immune sensing and signaling of cytosolic nucleic acids. Ann Rev Immunol. 2014;32:461-88.

38. Hemmi H, Takeuchi O, Kawai T, Kaisho T, Sato S, Sanjo H, et al. Erratum a toll-like receptor recognizes bacterial DNA. Nature 2001;409:646.

39. Arthur JS, Ley SC. Mitogen-activated protein kinases in innate immunity. Nat Rev Immunol. 2013;13:679-92.

40. Krug A, Rothenfusser S, Hornung V, Jahrsdorfer B, Blackwell $\mathrm{S}$, Ballas $\mathrm{ZK}$, et al. Identification of $\mathrm{CpG}$ oligonucleotide sequences with high induction of IFN- $\alpha / \beta$ in plasmacytoid dendritic cells. Eur J Immunol. 2001;31:2154-63.

41. Rothenfusser S, Hornung V, Krug A, Towarowski A, Krieg $\mathrm{AM}$, Endres $\mathrm{S}$, et al. Distinct $\mathrm{CpG}$ oligonucleotide sequences activate human $\gamma \delta \mathrm{T}$ cells via interferon- $\alpha /-\beta$. Eur J Immunol. 2001;31:3525-34.

42. Worku M, Morris A. Binding of different forms of lipopolysaccharide and gene expression in bovine blood neutrophils. J Dairy Sci. 2009;92:3185-93. 